\title{
Handling Rejection as Failure: Aspiring Writers Getting the Rejection Slip
}

\author{
Henrik Fürst
}

\begin{abstract}
Included in the definition of being an aspiring person is the risk of failure. Aspiring fiction writers are no exception. This article shows that the role of aspiring fiction writer involves managing three issues: the hope of being published, rejection by a publisher, and the perception of the rejection as a failure. Drawing on 47 interviews with fiction writers who have attempted to become first-time writers, the analysis shows that aspiring writers' responses to rejection are related to accepting and dismissing responsibility for having failed and admitting or dismissing the rejection as a perceived failure. Based on these findings, the article presents procedures associated with four main approaches to dealing with failure: conceding, excusing, justifying, and refusing. This conceptual framework for understanding failure contributes to a theoretical understanding of evaluation and valuation processes and their consequences and to empirical studies of rejection as career failure; it also systematizes and extends Goffman's work on cooling out strategies.
\end{abstract}

Key words: cooling out strategy; cultural worker; culture of success; evaluation and valuation; failure; rejection

\section{Introduction}

People with aspirations attempting to succeed regularly fail, and such failures are often linked to a rejection. Career termination due to rejection in sports (Ball 1976; Butt and Molnar 2009) and university education (Clark 1960) are but two examples of failing in the course of pursuing career aspirations. A particularly exposed category includes people who aspire to succeed in the cultural industries, where many try but most fail (Menger 1999, 2014; Mathieu 2012; McRobbie 2016). The aspirants end up having to manage the tension between the aspiration to succeed and the perceived failure of a rejection. The current article studies the consequences of evaluation

Henrik Fürst, Department of Sociology, Uppsala University, henrik.furst@soc.uu.se

(C) 2016 Author

LiU Electronic Press, DOI 10.3384/VS. 2001-5992.1642153

http://valuationstudies.liu.se 


\section{Valuation Studies}

and being evaluated by examining how aspiring fiction writers deal with tensions involved in hoping to be published and being rejected by a publishing house.

There is a huge difference between the number of people who aspire to be a first-time published fiction writer and those who actually become one. Every year, the largest publishing houses in Sweden for fiction debuts receive a couple of thousand manuscripts but publish fewer than ten debut fiction books. ${ }^{1}$ The 152 publishing houses in Sweden that announced fiction debuts between 1997 and 2014 published a combined average of 44 per year. This means that there are many failed attempts and a few successful ones in becoming a firsttime published fiction writer in Sweden.

In addition, only 1 percent of the debut fiction books published between 1997 and 2014 were first picked up by a literary agency and then sold to a publishing house. This contrasts starkly with the situation in the United States and the United Kingdom, where getting published through a literary agency is common (Thompson 2012: 7174). In Sweden, the most common publication route is for writers to send their manuscript directly to publishing houses. Publishing houses sometimes offer information on their websites about whether they accept unsolicited manuscripts from writers. They may also provide information on what they want, for example stating that they are only interested in poetry. Some publishing houses also indicate, in various ways, that they receive large numbers of manuscripts. When publishers have assessed a manuscript and decided to reject it, they usually send a rejection slip directly to the writer, which means that the writer needs to deal with the consequences of being assessed.

The tensions these rejections create for aspiring writers in Sweden can be understood in relation to individualism and, more specifically, living in a culture that is imbued with notions of success. Cultures of success are produced by the value of self-realization and a reliance on the belief that anyone can make it (Meizel 2009). In individualized cultures, success is not necessarily regarded as determined by structural opportunities and constraints (Menger 1999, 2014; Abbott 2005: 310). Rather, equal access is assumed, and people are encouraged to attempt to succeed in their aspirations (Merton 1938: 680; Clark 1960). While the continuation of the social system depends on individual efforts to succeed, contradictions to the idea that anyone can succeed are dealt with by adapting people to failure (Clark 1960). In the case of fiction writers, many people have spent a long time pursuing their aspirations and preparing their manuscripts, while publishers' answers are usually a direct and definite "yes" or "no." Thus, aspiring writers who have been emotionally and socially charged to succeed at getting published may perceive publishers' rejections as failures.

1 These figures represent fiction debuts presented between 1997 and 2014 in the Swedish publishing industry trade magazine Svensk Bokhandel. 
Publishers act as gatekeepers to the publishing market: they determine which aspiring writers will succeed and which will fail (Hirsch 1972; Coser 1975; Coser et al. 1982). Being admitted or denied entry is the objective side of artistic success and failure. But there is also a subjective side concerned with writers' experience of these assessments and the meanings they assign them. For many rejected writers, the felt experience of being assessed requires adapting to having failed.

Goffman (1952) has described this subjective side of failure in his research on how victims of confidence tricks adapt to failure. Like aspiring writers in cultures of success, the victims (or marks) are led to believe that they will earn a fast buck by carrying out some illicit task. However, they often end up failing and, as a consequence, lose their money. The game is rigged; con men plan the marks' failures from the outset. Goffman describes the last step in the game as adapting the mark to the failure through a process of "cooling the mark out" and thereby enabling marks to rationalize their failure. Goffman extends the metaphor of "cooling the mark out" to job transitions, marriage proposals, and many other phenomena. As Goffman shows, people in these situations have not necessarily been tricked. Similarly, publishers are seldom tricking writers when they reject a manuscript. Nevertheless, the culture offers a variety of "cooling out" strategies to rejected writers who perceive their rejection as failure, and writers use these strategies to handle their failure.

The present study analyzes how people deal with the consequences of being evaluated and rejected in an aspiration. For rejected writers, these consequences include having to manage the tension between having hoped to be published and being rejected. I introduce responsibility for and admitting or dismissing the perceived failure as key to understanding the cooling out strategies that writers use to deal with this tension. As my analysis shows, writers use four types of strategies to adapt to rejection: excusing, justifying, conceding, and denying failure.

\section{Previous Research}

Cultural industries attract people who want to engage in cultural work for the sake of joy, glamour, and creativity, but which often feature emotionally demanding working conditions and poor economic compensation (Hesmondhalgh and Baker 2008; Skov 2012; Hesmondhalgh 2013: 253-257; Conor et al. 2015; McRobbie 2016). Failure is a hidden reality of being a cultural worker (McRobbie 2016: 56) but is rarely studied. Unlike the few studies of creative failure that currently exist this article links the experience of failure to the creative person's process of adapting or failing to adapt to it. I develop a framework for studying how cultural workers deal with the regular 


\section{Valuation Studies}

occurrence of being rejected and seeing such rejection as failure. I focus on aspiring writers as an example of cultural workers who are especially prone to fail. Coping with failure is a major part of creative work, and understanding this process sheds light on a major consequence of winner-takes-all markets, in which many fail and must deal with not being among the chosen few.

The present study also extends the research on evaluation and valuation. Studies of evaluation and valuation usually investigate value assessment and creation (Beckert and Aspers 2011; Lamont 2012; Zuckerman 2012; Helgesson and Muniesa 2013; Vatin 2013), for example, of fine wines, films, literary works, and music (Karpik 2010) and of design school applicants and their work (Strandvad 2014). The present study begins after the value of the person and the manuscript has already been established and sheds light on the often overlooked consequences of these practices.

No research has yet investigated failure and adaption to failure among aspiring writers. However, scholars have studied cooling out failures related to other activities, such as sports (Ball 1976; Butt and Molnar 2009) and delays and waiting (Åkerström 1997; Sellerberg 2008). For instance, Ball (1976) shows that rejection and failure in sports are more easily cooled out when there are viable alternatives for the athletes. Others have studied cooling out among unpromising students (Clark 1960), terminated workers in outplacement programs (Miller and Robinson 2004), contestants in televised music competitions (van den Scott et al. 2015; Wei 2016), mothers of children with Down's syndrome (Thomas 2014), and men making advances on women in singles bars and nightclubs (Snow et al. 1991). In the latter case Snow et al. (1991) show that women use cooling out strategies to protect themselves and to let men down easily. These strategies include polite refusals, excuses, and jokes, and women use them both before and during unwanted advances. More persistent men are cooled out through defensive incivility, including callous rejections and self-evident justifications that clearly state the woman's lack of interest. Women use still other strategies to avoid unwanted advances in the first place; for example, they may indicate that they are in a committed relationship, or show a clear lack of interest through their body language, or by fleeing from the situation. Snow et al. (1991) show that cooling out strategies are implicitly linked to justifications and excuses; the present article elaborates this link.

This body of research focuses on expectations of and reactions to failure and on particular cooling out strategies. It shows that cooling out strategies are sometimes formalized in organizations (Clark 1960; Ball 1976; Åkerström 1997; Miller and Robinson 2004; Sellerberg 2008) and at other times, as in this article, are part of informal, reoccurring encounters between people or between people and organizations (Ball 1976; Snow et al. 1991; Butt and Molnar 2009; 
Thomas 2014; van den Scott et al. 2015; Wei 2016). While some studies focus on those who are engaged in cooling out (Clark 1960; Snow et al. 1991; Åkerström 1997; Miller and Robinson 2004; Sellerberg 2008), this article joins those others that focus on those being cooled out (Ball 1976; Butt and Molnar 2009; Thomas 2014; van den Scott et al. 2015; Wei 2016).

This article develops and demonstrates a conceptual scheme that outlines four ways that people deal with failure. In doing so, it contributes to three fields of research. The first and main contribution is its focus on adaption to failure as a consequence of the assessment of people and their work under market-like conditions. Second, this study contributes to the work of Goffman (1952) and his proponents by systematizing his formulation of cooling out strategies and by introducing additional strategies and procedures highlighted by the case of aspiring writers. Third, the scheme also contributes to the study of creative work and actors dealing with failure in careers in the creative industries.

\section{Four Ways of Dealing with Failure}

Objectively, the rejection of a manuscript is a failure: the publisher has clearly and explicitly rejected the manuscript. Subjectively, however, the writer may or may not perceive the rejection as a failure. Many writers have committed themselves to becoming published writers, and the publisher's rejection does not support this aspirational status (Goffman 1952: 452); the writer's expectations have not been fulfilled. Inconsistencies have appeared in the writer's course of action; these inconsistencies present a threat to the writer's face, and the writer may be embarrassed (Goffman 1967: 8-9; see also Ball 1976: 727) or ashamed. Shame shapes self-identity as people see themselves from the perspective of another and sense a lack of deference and a negative evaluation from the other (Cooley 1922: 184; Scheff 1990). However, shame is often unacknowledged and hidden in social interaction, which sometimes leads to a cycle of shame and anger (Scheff 1990). To be cooled out is to define the situation in a way that enables the person to handle the emotional impact of failure and its threat to a claimed self-identity.

From the perspective of a person cooling him- or herself out, four categories analytically distinguish cooling out strategies. The first two categories are excuses and justifications. Excuses and justifications are accounts used to deal with claims of having failed (Scott and Lyman 1968). Here, excuses and justifications are accounts that fiction writers use to cool themselves out and adapt to a perceived failure. As accounts, they are "employed whenever an action is subjected to valuative inquiry" because the action is unanticipated or untoward 


\section{Valuation Studies}

(Scott and Lyman 1968: 46; see also Austin 1956: 2)²-for example, when a manuscript is rejected and the rejection is perceived as a failure.

Excuses are accounts used when the person accepts the occurrence of failure but not responsibility for the failure (Austin 1956: 2; Scott and Lyman 1968: 47; Schönbach 1990: 79-80); excuses explain and rationalize the failure. An excuse is used to cool out a perceived failure by saying, for instance, that one has had a bad day, that one was not prepared, or that the failure was a clumsy mistake. Justifications are accounts used when the person dismisses the occurrence of failure but accepts responsibility for the failure (Austin 1956: 2; Scott and Lyman 1968: 47; Schönbach 1990: 80). For example, a writer might justify a rejection by claiming that it was an intended outcome. ${ }^{3}$

The second two types of cooling out strategies are concession and refusal of failure (Schönbach 1990: 78-80). ${ }^{4}$ When conceding failure, the person accepts the occurrence of the failure and the responsibility for it (Schönbach 1990: 78). The writer is either cooled out and has fully adapted to the failure or has realized that there has been a failure but has not adapted to it. The strategies involved in conceding failure include concrete courses of action, such as making a new attempt. While excuses and justifications are oriented toward the failure, concessions are about leaving the rejection behind by orienting oneself toward the future. A refusal means that the person is dismissing both the occurrence of failure and responsibility for having failed (Schönbach 1990: 80). For example, a writer might perceive the rejection as a failure but at the same time be unable to comprehend having been rejected, and this might signal that the writer is in need of cooling out, for example by being angry with the publisher.

\footnotetext{
2 Schönbach (1990: 5) defines an account "as a special explanation: an account is an answer to an explicit or implicit question guided by a normative expectation." The implicit question for writers failing to get published is, "Why did you get rejected?" and excuses and justifications are two types of answers to this question.

${ }^{3}$ Another example of justification is how people rationalize meat consumption and avoid feeling guilt when meat consumption is perceived as a failure. Piazza et al. (2015) have shown that people usually use four types of justification. Eating meat is nice, natural, necessary, and normal. Following the line of thought in this article, eating meat is a failure or something bad. The person claims responsibility for doing it, but denies that it is a failure or bad, since it is nice, natural, necessary, and normal.

4 Austin (1956) studies the language used to convey excuses or justifications as speech acts dealing with failure. According to Austin, excuses and justifications are used when a person has been accused of having done something wrong. They are related to taking or not taking responsibility for the failure (Austin 1956: 2). No one directly tells writers that they have done something wrong, but they may perceive the rejection as a failure and use excuses and justifications as accounts for why their work was rejected; these excuses and justifications may question whether a failure really has occurred and what their own responsibility for the failure has been.
} 
Thus cooling out strategies are directed at handling the failure either through accounts or by conceding them and creating new courses of action. Table 1 summarizes this conceptual scheme. ${ }^{5}$ This scheme makes it easier to understand and refine the variety of cooling out strategies that researchers have already identified and to describe additional strategies that new research uncovers. Below, I use this scheme to analyze how fiction writers deal with the tension between hoping to succeed and failing.

Accepting responsibility Dismissing responsibility

\begin{tabular}{c|l|l|}
$\begin{array}{c}\text { Accepting the } \\
\text { occurrence of } \\
\text { failure }\end{array}$ & $\begin{array}{l}\text { 1. Conceding } \\
\text { (Schönbach 1990: 78) }\end{array}$ & $\begin{array}{l}\text { 2. Excusing } \\
\text { (Austin 1956: 2; Scott } \\
\text { and Lyman 1968: 47; } \\
\text { Schönbach 1990: 79-80) }\end{array}$ \\
$\begin{array}{c}\text { Dismissing the } \\
\text { occurrence of } \\
\text { failure }\end{array}$ & $\begin{array}{l}\text { 3. Justifying } \\
\text { (Austin 1956: 2; Scott } \\
\text { and Lyman 1968: 47; } \\
\text { Schönbach 1990: 80) }\end{array}$ & $\begin{array}{l}\text { 4. Refusing } \\
\text { (Schönbach 1990: 80) }\end{array}$ \\
\hline
\end{tabular}

Table 1. Four ways of dealing with rejection as failure

Source: author's own illustration

\section{Data and Methods}

To understand how writers deal with rejection, I conducted four group interviews and 43 individual interviews in various parts of Sweden during 2013 and 2014. I interviewed several types of writers: writers who were aspiring to become published, writers who had aspired to become published and had either succeeded or failed, and writers who had not (yet) oriented themselves toward being published. ${ }^{6}$ I use pseudonyms for all writers to protect their anonymity.

\footnotetext{
5 See Schönbach (1990: 188-195) for a full taxonomy of concession, excuse, justification, and refusal as reactions in the context of interactional conflict.

${ }^{6}$ I also conducted interviews with literary agents and publishers or people working at publishing houses. I asked publishers and literary agents about both the fiction debut books they had published and the manuscripts they had rejected. For instance, sometimes they had manuscripts already submitted on their desks that they could talk about. During these interviews, I also observed how the submitted manuscripts were handled in the office space. Agents and publishers talked about procedures and different types of rejections and selections, for example how they formulated rejection letters and contacted writers. However, the main focus of this analysis is the writers themselves and their ways of dealing with failure.
} 


\section{Valuation Studies}

The first third of each interview consisted of open-ended questions about the interviewee's writing and orientation to becoming published. I then introduced a "career scheme template": a table with headings such as writing-school participation, literary mentors, writing projects, selections/rejections, and timescale. I checked for potential additional categories during the open-ended part of all the interviews and found no new categories after the first couple of interviews. I then asked the writer to fill out the template and talk about writing projects and selections and rejections of their work. Writers who had had such experiences then narrated what had happened before, during, and after a publishing house had selected or rejected their work. I developed a tentative conceptual scheme, resembling the one presented in this article, after the first seven interviews and used this scheme throughout the rest of the interviews, making it possible to both explore and develop the scheme.

I performed a first-cycle and a second-cycle coding (Saldaña 2013). The first coding cycle was to code and categorize the material into broadly different phases of a literary career. For the second-cycle coding, I used the theoretical outline of cooling out strategies; the outline focused on writers who had received a response from a publisher and the different roles involved in this process. I also analyzed the different scenarios of rejection and selection for publication. I then closely compared and analyzed the material and fitted it into the conceptual scheme. This way of developing existing theory in second-cycle coding is called elaborate coding, "where the goal is to refine theoretical constructs from a previous study" (Auerbach and Silverstein 2003: 104), leading to the use and elaboration of previous theoretical constructs and the development of new ones. ${ }^{7}$ The conceptual scheme is thus both an analytic result and a conceptual model linked to existing research.

\section{Analysis}

In what follows, I present my analysis of the phase after a publisher has rejected the writer's work. I focus on the strategies used by the writers themselves from their own perspective, since these are the most varied strategies in the material. Some writers used only one of these strategies, while others used several. Publishers and peers also sometimes offered cooling out strategies to failed aspiring writers; in these cases, I analyze the roles of these publishers and peers in relation to the writers' own perspective.

\footnotetext{
7 Some proponents of grounded theory have hinted at this type of coding procedure, in which the researcher is explicitly involved with existing theory and extant concepts (Strauss 1987: 306-311; Charmaz 2006: 64-65). A general procedure in grounded theory, however, involves using suggestive theoretical codes rather than explicitly extending existing theory (Charmaz 2006: 63-66).
} 


\section{Conceding rejection as failure}

Nowadays you can read your e-mail on your phone, and on my way home from work I saw the letter from the publishing house. I could not help myself, and I read it. It was a rejection. I went home, fixed a strong gin and tonic, and got drunk. That was my way of dealing with it. (Cecilia, aspiring writer)

Conceding failure happens when the writer has accepted that a failure has occurred and claims some or full responsibility for it. Writers who concede failure either are in need of cooling out or have already cooled out. As writers cool out, they may either withdraw from their aspiration or continue with it. If they are in need of cooling out, they have not coped with the failure, and their sense of pride has taken a blow. To concede failure, the writer might offer or be offered a new status, turn sour, use synthetic methods, perform magic and ceremonies, blow out steam, or plan to make a new attempt. When conceding the rejection as failure, the writers either involve themselves in rituals or give reasons why they should continue or not continue to pursue an aspiration to be published.

One way of dealing with the conceded failure is to be offered or to offer oneself another status or aspiration that is different from the one being rejected (Goffman 1952: 457; Clark 1960: 574-574; Ball 1976: 736; Thomas 2014: 293-295). One writer who had failed and initially had a hard time coping with the situation was offered a status as a writing teacher. The writer said, "It is common knowledge: 'Those who can, do; those who can't, teach"' (Anna, formerly an aspiring writer). The writer was then able to leave the situation of being a rejected aspiring writer and enter this new status as a teacher. At the same time as the writer's orientation shifted, she also came to accept the failure and her responsibility for it. For rejected writers, self-publishing can work in a similar way; in this case, writers offer themselves a status similar to the rejected status. In the words of Goffman, the writer can be understood to "gather about him the persons and facilities required to establish a status similar to the one he has lost, albeit in relation to different persons" (Goffman 1952: 459). A writer who had failed to be published by a publishing house for a number of years, said:

After two and half years, I had finally been rejected by all publishing houses. I felt that I was closing in to be published, but it gets harder and harder to be published through a publishing house as time goes on. I then decided to self-publish and started a journey to become a self-published writer. (Adam, published writer)

The writer then offered himself a new status and at the same time dealt with the failure of having been rejected by the publishing houses. These writers have conceded failure and are able to be cooled out by offering themselves a similar status, for example by becoming something else or by self-publishing. In so doing they soften the blow of being rejected and cope with having failed. 


\section{Valuation Studies}

Writers who have conceded failure can also deal with the situation by turning sour (Goffman 1952: 45). The writer outwardly appears to have conceded the situation as a failed attempt but has not fully dealt with the failure. This is a way of keeping the chin up and cooling out while at the same time withdrawing from the effort of getting published. A writer and her peers had thought that she would be published, but she says that after her work was rejected, "I do not talk about my own writing these days, not many people know that I write. I usually tell people that I have stopped writing [and do other fulfilling things] and that doing that is as fulfilling as writing" (Anna, formerly an aspiring writer). She said that she does this to get away from the pressure to try again and the blow of having failed at a time when she still had a hard time coping with the failure.

To cool out, the person can blow out steam (Goffman 1952: 457; Thomas 2014: 289-290). One crime novel writer became very upset when publishers rejected one of her manuscripts:

Interviewer: Returning to the rejections from the publishing houses, what did you think about the rejection letters when you got them?

Birgitta: I said, "Forget about the publishers! We can include the publishers in the next novel and kill them off." (Birgitta, published writer)

By telling her peers that she would symbolically kill the publishers who had rejected her work, she was able to blow off some steam and accept her failure. While turning sour is about appearing to accept the failure, blowing off steam is about strongly showing that one has not accepted it. Both strategies are based on conceding the failure and responding to the blow in different ways. Blowing off steam is not a reactive strategy for responding to rejection, as, for example, is exploding with anger. Instead, blowing off steam is a proactive strategy that writers use to overcome the sting of failure.

Writers can also use synthetic methods to cool out from a failure they have conceded-for example, by drinking alcohol. One such example was given by Cecilia in the opening of this section, where she had got drunk after having read a rejection e-mail on her phone. She conceded her failure and did not find any excuses or justifications for it, and she dealt with it by attempting with the help of alcohol not to think about it.

Another way to overcome the failure is to perform ceremonies or, in Malinowski's (1954) words, magic. The writer who planned to symbolically kill off the publishers drew on the idea of magic in imagining such an endeavor. Another writer used a ceremony and magic more concretely; he said, "I invited my friends to a party and set the manuscript and the rejection letters on fire". This symbolic act helped him "get over the rejection and get on with [his] life" (Simon, aspiring writer). Another writer told a similar story: "My literary 
mentor ripped the rejection letters apart. [...] It was like a therapeutic intervention" (Anna, formerly an aspiring writer). These ceremonies and magic were meant to literally and symbolically destroy the sign of failure to enable the writers to overcome a situation they have conceded as a failure.

Peers may become involved as coolers when they hear about the rejected writers' grievances concerning the rejection. Peers can console the writer by providing excuses, justifications, refusals, as well as concessions. In the excerpt below, a writer describes his peers as helping him concede the failure (see also Clark 1960: 575; Thomas 2014: 291-293):

Interviewer: Did you talk to anyone about these rejections?

Daniel: Yes. I talked to my wife and a few friends.

Interviewer: What did they say?

Daniel: My wife said that it must hurt, and I knew she really felt for me. Then I mentioned it to a friend in another context, and I felt like they understood my pain. It feels like not many people understand this kind of pain. (Daniel, published writer)

The writer's partner and friends were able to console the writer and give him social support that helped him concede and adapt to his failure. Another rejected writer consulted the members of her writing group, who said, "Just do it again." They were very supportive; "without them, I wouldn't have been published today. I wouldn't have managed to go on" (Emma, published writer). The writing group's social support helped this writer cope with her failure by encouraging her to plan to make a new attempt (Goffman 1952: 457). In a similar fashion, publishers can act as coolers. Their main strategy as organizations is to stall (Goffman 1952: 458; see also Clark 1960: 575; Sellerberg 2008) by giving the impression in the rejection letter that they might be interested in publishing the rejected writer's work in the future. This stalling strategy helps rejected writers cope with their failure by implicitly offering them a chance to try again.

\section{Excusing rejection as failure}

Everyone gets rejection letters. (Jonas, published writer)

An excuse happens when the writer has accepted the occurrence of failure but does not claim full responsibility for having failed. In practice, this means having been rejected by a publisher but not accepting responsibility for the failure. Writers who excuse rejection may or may not be correct in their claim that the rejection was not 


\section{Valuation Studies}

their responsibility. The writers I interviewed used the following strategies to excuse rejection: claiming unclear evaluation criteria; claiming clear but wrong evaluation criteria; and claiming that everyone fails. Excusing rejection as failure involves giving reasons why the manuscript was rejected.

Writers who claimed unclear evaluation criteria argued that publishers do not know what they are doing and are making mistakes when they select and reject manuscripts. One concrete excuse was to use exemplars of well-known writers who were first rejected and then became successful, published writers. In a group interview, four writers developed and used a strategy of unclear evaluation criteria to handle one of the participants' rejection:

Gerd: What if the publishing houses actually would do a different kind of assessments of your manuscript? One publishing house would like to publish it, and another would not like to publish it. Why would one response be worth more than the other?

Stina: The ambition is to have it published.

Gerd: The manuscript might be rejected by some publishing houses, but there may also be fifteen other publishing houses that would like to publish it, saying "How it is even possible that this manuscript was once rejected?"

Fanny: Wasn't it [Astrid Lindgren's book] Pippi Longstocking that got rejected? (Gerd: Yes, it was.) She sent it to one publisher who rejected it and then to another one who selected it.

Hanna: Yes, that is the case for most writers. Most writers get rejected by publishers. (Stina, Gerd, Fanny, and Hanna, aspiring writers)

The writers discuss the unclear evaluation criteria at publishing houses and make the case that well-known writers have initially been rejected. The rejection of Pippi Longstocking could also have been used as an example of "everyone fails" or "even the best writers fail". However, in the above quote, the illustrative rejection is used to present the uncertainty that prevails in the publishing market and the difficulty that this uncertainty causes for publishing houses in their search for "good" manuscripts. This interpretation makes the rejection of a writer's manuscript a case of unclear evaluation criteria. The writers use previous mistakes by publishers as an excuse for the current failure; the implicit argument is that the publishers have made a mistake. This strategy recalls Goffman's (1952: 456-457) discussion of people with similar status to the marks who are used to cool the mark out. Here, the writers use a published writer as an exemplar of similar status to the rejected writer. Through an act of imagination, the writers use a past situation as an excuse that makes it possible to deal with the 
failure; they imagine that the rejection was wrong and that it might be part of a longer-term success story.

Other excuses concerning unclear evaluation criteria have to do with having the wrong timing and the fact that people read manuscripts differently. This means that the writer is not responsible for having failed because the rejection was just the result of a different reading of the manuscript, and the manuscript itself might still be good and publishable. The response to the failure may then be to say, "It's their loss." One writer expressed this sentiment:

Inger: I got a rejection where the publisher said I should read the greatest novelists of our time, and then I will learn how to write well. I became upset; I thought I was a really good writer [...]

Interviewer: Did you change your way of writing after this rejection?

Inger: No, actually, I did not. I do not want to be published because I write as the publishers want me to write. I write the things I feel like writing, and I have a uniqueness in my way of writing, like everyone else in my writing group. I value this uniqueness, and that is why I am part of a writing group. (Inger, published writer)

Inger knows she has failed but says that it is the publishing houses' loss if they do not want to publish her texts. Self-publishing can work as a similar type of excuse to cool out the failure of having been rejected by a traditional publisher. The status denied by the traditional publisher is created by the writers themselves, sometimes with a sentiment of "I will show them"; that is, the writer will show the publishers that deciding not to publish their work was the wrong decision.

Another excuse is to say, as writer Hanna does above, that most writers are rejected or, as another writer said, "Everyone gets rejection letters" (Jonas, published writer). Everyone fails means not only that writers now famous have been rejected, but also that everyone who submits a manuscript has been rejected. This does not necessarily have to do with unclear evaluation criteria-it's simply a claim that all writers fail, including this writer. The strategy is to remove the personal feeling of failure and instead talk about it as a general and common event. To be rejected is then at least not a personal failure; the responsibility is not on the shoulders of the individuals themselves. As an objective failure, a rejection is always a sign of having attempted to do something that failed. But individuals may not interpret objective failures as personal failures-they might even see them as personal successes.

Alternatively, the rejected individual might claim that the evaluation criteria were clear but wrong. One aspiring writer said, when asked how he had reacted when he was rejected, "Yes, of course, 


\section{Valuation Studies}

you get a bit disappointed. You have expectations. As I said before, [for publishers] it might be about earning money quickly" (Karl, aspiring writer). Here, the writer excuses the failure by saying that the publishers might have only been interested in potential best-sellers. Another writer said, "[Publishers publish] things of inferior quality because the person who has written it is a bit famous. Then they just publish it" (Lars, published writer). This writer excuses the failure of rejection by claiming that publishers prefer work written by celebrities. In both cases, the evaluation criteria are clear-it is the potential bestseller or the manuscript written by a famous person that gets selected -but these criteria are leading publishers to select the wrong manuscripts. With this excuse, writers can cool out by claiming that the rejection was not a failure, since their manuscript might still be better (and more publishable) than the manuscripts getting published.

\section{Justifying the attempt and denying failure}

I would not like to have been published and then forgotten. (Nils, formerly aspiring writer)

A justification is made when the person accepts the responsibility of having been rejected but denies that a failure has occurred. The writer accepts the rejection but at the same time argues that it was not a bad thing. The writers I interviewed justified their rejections by defining the situation as a good attempt, hedging, relativizing, and reconstructing in hindsight. Justifications offer reasons why being rejected is actually not a bad thing.

If the rejection letter deviated in any sense from the standard rejection letter, writers could use it to justify the rejection as not a real failure. The submission might have been a good attempt. The writer might then feel a new hope to be published one day, as expressed by this writer:

Interviewer: How did you know that [a large publishing house] was interested in your work?

Maud: I understood it when I read the rejection letter. I did not get the standard rejection. "We have read your manuscript. Thank you, but we are not interested in publishing your work." They described the plot a bit and asked me to work on it some more. I worked on it some more and got a long letter with a review of my work. I was like "Wow, this is fun." I thought that if I worked some more on this manuscript and sent it to a lot of publishing houses, it would be accepted someday. (Maud, published writer)

Writers interpret these kinds of rejection letters as rejections but not as total failures. They justify them by claiming responsibility for having failed but claiming that the failure was not bad. An objective failure has occurred, but the person does not perceive it as a subjective failure. 
Another justification strategy is to claim that the submission was not a real attempt. This claim recalls Goffman's (1952: 461) notion of hedging, in which the person makes sure to avoid totally committing to achieving something. Writers may conceal their commitment to being published from others and even from themselves. When I asked a writer what his first thought was when his work was rejected, he said, "My first thought when I got the rejection letter was that it was one less rejection letter to think about" (Karl, published writer). The writer had from the outset contemplated the opportunity to self-publish but, despite this, had sent the manuscript to a traditional publisher. $\mathrm{He}$ justified the rejection as not really a bad thing because he had not expected the manuscript to be published by a traditional publisher anyway, and so the rejection was not that important or particularly bad. Although the writer contemplated and eventually decided to selfpublish, he would still have preferred to be published by a publishing house. He said:

I dreamed about getting published by a publishing house, and when I finished my manuscript I just did like everyone else and submitted it to publishing houses, who rejected it. I then just continued by self-publishing it, making it possible for me to hold the printed book in my hands.

As I interpret the writer's responses, he was still committed to being published by a traditional publisher, but for the hedging to work as a justification of the failure, he had to avoid fully expressing this commitment.

Relativization is a way of using justification to distance oneself from a rejection. The writer can claim after a rejection that becoming published is not the only thing that is important in life (cf. Goffman 1952: 455). "I do not think my life will be a failure if I am not published," one writer said, "and that was an important insight [...] it is important to get distance and see that a person is more than his or her writing, there are other things you can do" (Anna, formerly aspiring writer). Here, the writer's formerly total commitment to becoming a first-time published fiction writer is not salient; she justifies the failure by stating that it is not particularly bad and thus protects herself by distancing herself from the commitment.

Rejections can also be turned around; an initial failure can be turned into a success. This is a form of reconstructing in bindsight, which is related to eulogy work. Eulogy work is a strategy for coping with failure and managing emotion and reputation when one has lost an esteemed status in public by claiming the loss was not really a bad thing (van den Scott et al. 2015). In contrast to eulogy work, reconstructing in hindsight is not done immediately or for public display, and the writer has not lost a status but instead has failed to claim an aspirational status. For example, rejected writers might engage in reconstructing in hindsight when another publishing house 


\section{Valuation Studies}

publishes their work or if they rethink their priorities and what is important in life. They may even claim to be happy not to have been published, because the publication may have been a failure. As one writer said, "I would not like to have been published and then forgotten" (Nils, formerly aspiring writer). Another writer discussed the consequences of having been rejected and in hindsight reconstructed the meaning of her rejection:

If the manuscript of my novel had been published back then, I think it would have been uncomfortable for me today [...] I did not think about it then, but if it had been published then, everyone would have read a text that actually was quite a private matter. (Ulrika, formerly an aspiring writer)

Several years had passed since this writer's work had been rejected. By the time of the interview, she had reconstructed the rejection in hindsight by turning her initial perception of it as a failure into a feeling of relief.

\section{Refusing to see the rejection as a failure}

The writer who dismisses the failure and denies responsibility for it is unable to comprehend the situation as a failure and may eventually search for reasons why he or she failed. The writer may say, "I am right; they are wrong." One writer told me, "I had previously published a [non-fiction book]. When I published it, [the publisher] said, 'If you do anything more, something like fiction, I want to see it first.' 'You will see it first,' I said." She continued:

I was so angry when I was rejected [by the publisher]. I was furious. I was going out [for an event] in the evening, but I just wanted to knock someone to the ground.

Interviewer: Were you angry because you assumed you would be published?

Olga: Yes, because I was not that upset when I got rejections from the other publishing houses. When I got their rejections, it was not such a big deal. (Olga, published writer)

The writer had felt that the publisher had made an implicit promise to publish her work in the future, so when her manuscript was rejected, she could not comprehend it. The publisher was the one that did "not understand a thing"; the writer simply could not fail. This meant that the writer was getting "hot" and that conceding, excusing, or justifying the failure might cool her out. A writer who refuses a rejection is therefore not cooled out and has not adapted to the failure, while those deploying justifications, excuses, and concession are using strategies to adapt themselves to the failure. While some writers may fully adapt to a failure, others may never fully do so. 


\section{Discussion}

The writers I interviewed dealt with the failure of rejection in four main ways and by using a number of previously explored and not yet explored procedures. This conceptual framework systematizes Goffman's (1952) account of how people using cooling out strategies adapt to failure. It also brings additional perspective to the study of evaluation and valuations by linking their consequences to the experience of failure. Finally, this study contributes to research on careers in creative industries by linking experiences of failure to objective failures.

There is a lack of clear aesthetic standards for evaluating works of fiction (Anheier and Gerhards 1991a: 812-813, 1991b: 139-140; Janssen 2001: 340; Menger 2014: 4). The lack of clear aesthetic standards creates situations in which rejected writers cannot easily determine how publishers have assessed their manuscripts. Because of this uncertainty, writers attempt to make sense of what has happened and why their work has been rejected. They use excuses to find reasons for the rejection. Because the excuse makes it possible to imagine why the manuscript was rejected, the excuse transforms uncertainty into a resource for dealing with failure. For instance, rejected writers imagine and handle the failure by stating the excuse that publishers only select potential best-sellers or manuscripts written by celebrities. Rejected writers who refuse the rejection, on the other hand, are responding directly to the lack of clear evaluative criteria. They cannot imagine why their work was rejected; such a thing simply could not have happened. Justifications leave uncertainty aside and focus on the consequences of the rejection; they claim that in its consequences, the rejection was simply not that bad. Concessions attempt neither to grapple with the uncertainty nor to determine what could have happened. Instead, through concessions, rejected writers use rituals and strategies to overcome the failure and come up with reasons why they should or should not continue to pursue their aspiration to be published. A temporal sequence of adapting to failure appears: writers move from not comprehending the rejection (refusal), to focusing on why their work was rejected (excuses), to why, in its consequences, the rejection is not that bad (justification), to reorientation (concession). However, different strategies and sequences are in play; some people may use several different strategies at once, and the strategies used may depend on the situation and persons involved.

Because there are many aspiring writers who attempt to get published and whose work is rejected by a publishing house, the strategies and procedures presented here are commonly performed. Publishers' rejection slips are delivered privately to writers, and writers sometimes conceal the rejection. The consequences of assessment and rejection are not limited to aspiring writers, however, and can 


\section{Valuation Studies}

sometimes be of a more public nature. An example that is structurally analogous to that of aspiring writers who have failed is aspiring singers who fail in reality television music competitions (e.g., Idols/ Superstar). Thousands of aspiring singers participate in auditions to have their abilities assessed by a jury. They hope to succeed, but most end up failing (Meizel 2009: 485; Wei 2016). Participants who are rejected after the first round cool themselves out by justifying their failure, arguing that they are an unrecognized talent, and continuing to aspire to be recognized for their talents (Wei 2016). As cultures of success and evaluation and valuation play out, the stories of rejections and humiliation become part of the narrative plot and appeal of the program (Meizel 2009). The value lies in the public nature of the auditions and in what Garfinkel (1956) has called status degradation ceremonies, in which participants lose their claimed status in front of others. Participants save face by claiming in an exit ritual that what happened was actually good (van den Scott et al. 2015). There might be specific strategies for cooling out aspirants so that they maintain their identity and for destroying aspirants and their claimed identity after an assessment (Ball 1976: 727). In contrast to the aspiring writers' rejections, which are concealed, the program has created entertainment value from public evaluations and valuations (see also Muniesa and Helgesson 2013). Audiences are entertained by both failure and success, and the participants themselves might be mortified or in a state of celebration. Failure and success depend on each other in this context; a singer can only succeed if someone else fails and can only fail if someone else succeeds. While the failure, in this case, is a public event, the rejection from publishers is handled through the more private process of cooling out.

What happens when aspiring writers and singers attempt to succeed but continually fail? Another structurally analogous example is internet daters. Some internet daters hope to meet a romantic partner but end up failing in their aspiration to be matched with someone. In the face of recurring failures, daters may either learn to control their feelings of hope and failure (Fürst 2013) or be unable to control their feelings and thus be in need of cooling out (Snow et al. 1991). ${ }^{8}$ The consequences of evaluation and valuation might then lead to a gradual emotional distancing from the situation of evaluation and valuation and the risk of rejection (Fürst 2013). This connects with existing and possible future research on the consequences of being assessed in other fields.

In education, for example, reactions to university rankings have intended and unintended consequences for the universities involved, and these universities come to adapt their practices to these rankings (Espeland and Sauder 2007). Future research might explore the

8 It might, however, be possible to organize hope of success by instilling such an emotional climate within a group or organization (Fürst and Kümmel 2011). 
consequences of other kinds of evaluation in education including, for example, rejections of articles, book proposals, and grant proposals and rejections from aspirational academic positions. This brief summary of research on the consequences of evaluation seems to hint at a larger and perhaps promising field within valuation studies in which the consequences of assessment and being assessed are studied.

\section{Conclusion}

This article has shown that rejected writers manage the tension between having hoped to be published and being rejected by claiming responsibility and admitting or dismissing the perceived failure. The discussion showed the potential of studying the responses and strategies that people use to handle the intended and unintended consequences of evaluation.

A suggestion for further research is to extend this article's conceptual apparatus for understanding perceived failure to the study of success. Goffman (1952: 454) mainly analyzes adaption to failure but notes the possibility of promotion to a new status. Austin (1956) analyzes accusations of having failed, and Scott and Lyman (1968) study accounts of unanticipated or untoward actions; but it would be possible to study corresponding successes. Four different scenarios may arise that reverse the actions of conceding, excusing, justifying, and refusing. First, the success may be accepted (one has succeeded), and the person may claim responsibility for having succeeded; for example, the writer may fully adjust to having succeeded at getting published and accept the situation as such. Second, the success may also be accepted without any claim of responsibility; for example, the writer may attribute the success to someone else's actions and define it as not a real success. Third, the success may be refuted but the person may claim responsibility for having succeeded; for example, the writer may say that getting published was not the experience he or she had expected it to be. Fourth, the writer may not accept the success and may refrain from assuming responsibility for it, for example, by wanting to forget all about it. Future studies of success can empirically test and use this outline.

Another, more direct way to develop this research is to further analyze sequences of adaption to failure and success by following research procedures developed in social sequence analysis (Cornwell 2015). For example, researchers might examine how often and when people use different strategies or certain sequences of strategies and procedures (cf. Piazza et al. 2015), as well as how the different strategies are sequentially organized in talk (cf. Cerulo and Ruane 2014). Resulting patterns may indicate whether different social groups use similar or dissimilar strategies to cope with failure and success. Additional research would also be needed to understand when and 


\section{Valuation Studies}

how actors come to act out one or another of the strategies after having been rejected or selected. Such research might identify which structural factors shape the labor markets of creative industries, who attempts to access the labor market and with what consequences, and how failure and success in this labor market are shaped by structural inequalities (Hesmondhalgh and Saha 2013; Oakley 2013; Gill 2014; Conor et al. 2015; Saha 2015; McRobbie 2016). The consequences for the identities of those who are rejected or selected could also be studied. For instance, those rejected may be considered to be nonpersons or nobodies (Goffman 1963: 84); in this case, actors within the core of the literary world might behave with civil inattention in not recognizing the existence of the person. This could be contrasted to how a person becomes a "somebody" in the literary world and the consequences of evaluation and valuation of this identity. Such a study would investigate how people are identified and positioned by the identities that are produced and recognized within the literary world.

An individual's commitment to an aspiration is presumably influenced by how he or she deals with the consequences of being the object of an assessment. This research is thus important not only for the study of careers in cultural industries (see Mathieu 2012), but also for the study of aspiration and commitment to becoming something in general. Failures and methods of dealing with failure tap into fundamental conditions of living as a social being.

Acknowledgments. I thank the anonymous reviewers and the coEditor-in-Chief Claes-Fredrik Helgesson for their valuable feedback on earlier versions of this article. I also thank the participants of the Cultural Matters Group and The Uppsala Laboratory of Economy Sociology at Uppsala University for their comments. The research reported in this study has been part of a larger research project funded by a European Research Council Starting Grant (ERC 263699-CEV).

\section{References}

Abbott, Andrew. 2005. "The Sociology of Work and Occupations." In The Handbook of Economic Sociology, 2nd ed, edited by Richard Swedberg and Neil J. Smelser, 307-330. New York and Princeton, NJ: Russell Sage Foundation and Princeton University Press.

Åkerström, Malin. 1997. "Waiting: A Source of Hostile Interaction in an Emergency Clinic.” Qualitative Health Research 7(4): 504-520.

Anheier, Helmut K., and Jürgen Gerhards. 1991a. "Literary Myths and Social Structure." Social Forces 69(3): 811-830.

—. 1991b. "The Acknowledgment of Literary Influence: A Structural Analysis of a German Literary Network.” Sociological Forum 6(1): 137156. 
Auerbach, Carl F., and Louise B. Silverstein. 2003. Qualitative Data: An Introduction to Coding and Analysis. New York: New York University Press.

Austin, John Langshaw. 1956. "A Plea for Excuses: The Presidential Address." Proceedings of the Aristotelian Society 57: 1-30.

Ball, Donald W. 1976. "Failure in Sport." American Sociological Review 41(4): 726-739.

Beckert, Jens, and Patrik Aspers. 2011. The Worth of Goods: Valuation and Pricing in the Economy. New York: Oxford University Press.

Butt, Joanne, and Gyozo Molnar. 2009. "Involuntary Career Termination in Sport: A Case Study of the Process of Structurally Induced Failure." Sport in Society 12(2): 240-257.

Cerulo, Karen A., and Janet M. Ruane. 2014. "Apologies of the Rich and Famous Cultural, Cognitive, and Social Explanations of Why We Care and Why We Forgive." Social Psychology Quarterly 77(2): 123-149.

Charmaz, Kathy. 2006. Constructing Grounded Theory: A Practical Guide through Qualitative Analysis. London: SAGE.

Clark, Burton R. 1960. "The 'Cooling-Out' Function in Higher Education.” American Journal of Sociology 65(6): 569-576.

Conor, Bridget, Rosalind Gill, and Stephanie Taylor. 2015. "Gender and Creative Labour." The Sociological Review 63: 1-22.

Cooley, Charles Horton. 1922. Human Nature and the Social Order. New York: Scribner.

Cornwell, Benjamin. 2015. Social Sequence Analysis: Methods and Applications. New York: Cambridge University Press.

Coser, Lewis A. 1975. "Publishers as Gatekeepers of Ideas." The ANNALS of the American Academy of Political and Social Science 421(1): 14-22.

Coser, Lewis A., Kadushin, Charles, and Walter W. Powell. 1982. Books: The Culture and Commerce of Publishing. New York: Basic Books.

Espeland, Wendy Nelson, and Michael Sauder. 2007. "Rankings and Reactivity: How Public Measures Recreate Social Worlds." American Journal of Sociology 113(1): 1-40.

Fürst, Henrik. 2013. "Emotional Socialization on a Swedish Internet Dating Site: The Search and Hope for Happiness." In Internet and Emotion, edited by Tova Benski and Eran Fisher, 99-112. London: Routledge.

Fürst, Henrik, and Gerhard Kümmel. 2011. "Emotions: A Neglected Dimension in the Expeditionary Mindset." In Core Values and the Expeditionary Mindset: Armed Forces in Metamorphosis, edited by Henrik Fürst and Gerhard Kümmel, 215-223. Baden-Baden: Nomos.

Garfinkel, Harold. 1956. "Conditions of Successful Degradation Ceremonies." American Journal of Sociology 61(5): 420-424.

Gill, Rosalind. 2014. "Unspeakable Inequalities: Post Feminism, Entrepreneurial Subjectivity, and the Repudiation of Sexism among Cultural Workers." Social Politics: International Studies in Gender, State \& Society 21(4): 509-528. 


\section{Valuation Studies}

Goffman, Erving. 1952. "On Cooling the Mark Out: Some Aspects of Adaptation to Failure." Psychiatry 15(4): 451-463.

-1963. Behavior in Public Places: Notes on the Social Organization of Gatherings. New York: Free Press of Glencoe.

Goffman, Erving. 1967. Interaction Ritual: Essays on Face-to-Face Behavior. Garden City, NY: Doubleday.

Helgesson, Claes-Fredrik, and Fabian Muniesa. 2013. "For What It's Worth: An Introduction to Valuation Studies." Valuation Studies 1(1): 1-10.

Hesmondhalgh, David. 2013. The Cultural Industries. London: SAGE.

Hesmondhalgh, David, and Sarah Baker. 2008. "Creative Work and Emotional Labour in the Television Industry." Theory, Culture \& Society 25(7-8): 97-118.

Hesmondhalgh, David, and Anamik Saha. 2013. "Race, Ethnicity, and Cultural Production." Popular Communication 11(3): 179-195.

Hirsch, Paul M. 1972. "Processing Fads and Fashions: An Organization-Set Analysis of Cultural Industry Systems." American Journal of Sociology 77(4): 639-659.

Janssen, Susanne. 2001. "The Empirical Study of Careers in Literature and the Arts." In The Psychology and Sociology of Literature: In Honor of Elrud Ibsch, edited by Dick Schram and Gerard Steen, 323-357. Amsterdam and Philadelphia, PA: J. Benjamins.

Karpik, Lucien. 2010. Valuing the Unique: The Economics of Singularities. Princeton, NJ: Princeton University Press.

Lamont, Michèle. 2012. "Toward a Comparative Sociology of Valuation and Evaluation.” Annual Review of Sociology 38: 201-221.

McRobbie, Angela. 2016. Be Creative: Making a Living in the New Culture Industries. Cambridge: Polity Press.

Malinowski, Bronisław 1954. Magic, Science and Religion and Other Essays. Garden City, NY: Doubleday.

Mathieu, Chris, ed. 2012. Careers in Creative Industries. New York: Routledge.

Meizel, Katherine. 2009. "Making the Dream a Reality (Show): The Celebration of Failure in American Idol." Popular Music and Society 32(4): 475-488.

Menger, Pierre-Michel. 1999. "Artistic Labor Markets and Careers.” Annual Review of Sociology 25: 541-574.

- 2014. The Economics of Creativity: Art and Achievement under Uncertainty. Cambridge, MA: Harvard University Press.

Merton, Robert K. 1938. "Social Structure and Anomie." American Sociological Review 3(5): 672-682.

Miller, Michael V., and Cherylon Robinson. 2004. "Managing the Disappointment of Job Termination: Outplacement as a Cooling-Out Device." The Journal of Applied Behavioral Science 40(1): 49-65.

Muniesa, Fabian, and Claes-Fredrik Helgesson. 2013. "Valuation Studies and the Spectacle of Valuation." Valuation Studies 1(2): 119-123. 
Oakley, Kate. 2013. "Absentee Workers: Representation and Participation in the Cultural Industries.” In Theorizing Cultural Work: Labour, Continuity and Change in the Cultural and Creative Industries, edited by Mark Banks, Rosalind Gill, and Stephanie Taylor, 56-67. New York: Routledge.

Piazza, Jared, Matthew B. Ruby, Steve Loughnan, Mischel Luong, Juliana Kulik, Hanne M. Watkins, and Mirra Seigerman. 2015. "Rationalizing Meat Consumption. The 4Ns." Appetite 91: 114-128.

Saha, Anamik. 2015. "The Marketing of Race and Ethnicity in the Cultural Industries." In The Routledge Companion to the Cultural Industries, edited by Justin Connor and Kate Oakley, 512-521. London: Routledge.

Saldaña, Johnny. 2013. The Coding Manual for Qualitative Researchers. London: SAGE.

Scheff, Thomas J. 1990. Microsociology: Discourse, Emotion, and Social Structure. Chicago, IL: University of Chicago Press.

Schönbach, Peter. 1990. Account Episodes: The Management or Escalation of Conflict. Cambridge: Cambridge University Press.

Scott, Marvin B., and Stanford M. Lyman. 1968. "Accounts." American Sociological Review 33(1): 46-62.

Sellerberg, Ann-Mari. 2008. "Waiting and Rejection: An Organizational Perspective 'Cooling Out' Rejected Applicants.” Time \& Society 17(2-3): 349-362.

Skov, Lise. 2012. "It Was a Huge Shock: Fashion Designers' Transition from School to Work in Denmark, 1980s-2000s." In Careers in Creative Industries, edited by Chris Mathieu, 270-288. New York: Routledge.

Snow, David A., Cherylon Robinson, and Patricia L. McCall. 1991. "'Cooling Out' Men in Singles Bars and Nightclubs: Observations on the Interpersonal Survival Strategies of Women in Public Places." Journal of Contemporary Ethnography 19(4): 423-449.

Strandvad, Sara Malou. 2014. "Contingencies of Value: Devices and Conventions at a Design School Admission Test." Valuation Studies 2(2): 119-151.

Strauss, Anselm L. 1987. Qualitative Analysis for Social Scientists. Cambridge: Cambridge University Press.

Thomas, Gareth M. 2014. "Cooling the Mother Out: Revisiting and Revising Goffman's Account.” Symbolic Interaction 37(2): 283-299.

Thompson, John B. 2012. Merchants of Culture: The Publishing Business in the Twenty-First Century. Cambridge: Polity Press.

van den Scott, Lisa-Jo K., Clare Forstie, and Savina Balasubramanian. 2015. "Shining Stars, Blind Sides, and 'Real' Realities Exit Rituals, Eulogy Work, and Allegories in Reality Television." Journal of Contemporary Ethnography 44(4): 417-449.

Vatin, François. 2013. "Valuation as Evaluating and Valorizing." Valuation Studies 1(1): 31-50.

Wei, Junhow. 2016. "I'm the Next American Idol': Cooling Out, Accounts, and Perseverance at Reality Talent Show Auditions." Symbolic Interaction 39(1): 3-25. 


\section{Valuation Studies}

Zuckerman, Ezra W. 2012. "Construction, Concentration, and (Dis) Continuities in Social Valuations." Annual Review of Sociology 38(1): $223-245$.

Henrik Fürst is a doctoral candidate in the Department of Sociology at Uppsala University. His research is in the fields of sociology of culture and economic sociology, and focuses on cultural evaluation under conditions of quality uncertainty. His dissertation is about the Swedish publishing market and how aspiring fiction writers and publishers deal with the quality uncertainty of manuscripts. 